\title{
Contribution of Cutoff Lows to Precipitation across the United States*
}

\author{
JOHN T. ABATZOGLOU \\ Department of Geography, University of Idaho, Moscow, Idaho
}

(Manuscript received 15 September 2015, in final form 28 December 2015)

\begin{abstract}
A chronology of cutoff lows (COL) from 1979 to 2014 alongside daily precipitation observations across the conterminous United States was used to examine the contribution of COL to seasonal precipitation, extremeprecipitation events, and interannual precipitation variability. COL accounted for between $2 \%$ and $32 \%$ of annual precipitation at stations across the United States, with distinct geographic and seasonal variability. The largest fractional contribution of COL to precipitation totals and precipitation extremes was found across the Great Plains and the interior western United States, particularly during the transition seasons of spring and autumn. Widespread significant correlations between seasonal COL precipitation and total precipitation on interannual time scales were found across parts of the United States, most notably to explain spring precipitation variability in the interior western United States and Great Plains and summer precipitation variability in the northwestern United States. In addition to regional differences, a distinct gradient in the contributions of COL to precipitation was found in the lee of large mountain ranges in the western United States. Differences in orographic precipitation enhancement associated with slow-moving COL resulted in relatively more precipitation at lower elevations and, in particular, east of north-south-oriented mountain ranges that experience a strong rain shadow with progressive disturbances.
\end{abstract}

\section{Introduction}

Interannual variability in precipitation plays an important role in shaping water resource management. Several factors contribute to interannual precipitation variability, including those tied to coupled oceanatmosphere modes of climate variability. A few large precipitation events can contribute a sizeable portion of climatological precipitation (e.g., Dettinger et al. 2011), however, as well as interannual precipitation variability (e.g., Lute and Abatzoglou 2014). In addition, specific atmospheric circulation patterns such as atmospheric rivers account for a substantial portion of annual precipitation (e.g., Rutz et al. 2014), precipitation and hydrologic extremes (e.g., Ralph et al. 2006), and interannual variability in precipitation (Dettinger

\footnotetext{
* Supplemental information related to this paper is available at the Journals Online website: http://dx.doi.org/10.1175/JAMCD-15-0255.s1.

Corresponding author address: John T. Abatzoglou, University of Idaho, Dept. of Geography, 875 Perimeter Drive, MS 3021, Moscow, ID 83843-3021.

E-mail: jabatzoglou@uidaho.edu
}

et al. 2011; Dettinger 2013) across parts of the western United States.

This study focuses on cutoff upper-level low pressure systems as a distinct atmospheric circulation pattern. Cutoff lows (COL) are a subset of closed upper-level troughs that detach equatorward of the westerly current, often as a by-product of Rossby wave breaking (Ndarana and Waugh 2010), equatorward-propagating filaments of high-potential-vorticity air (Wernli and Sprenger 2007), and other amplified flow regimes such as blocking (e.g., Nieto et al. 2007). COL have distinct geographic and seasonal distributions (e.g., Nieto et al. 2005) synchronized with variations in upper-tropospheric flow. Once a COL is displaced from the main waveguide, it lacks means to propagate and consequently often remains quasi stationary, or even retrogrades, and either is dissolved as a result of friction or diabatic heating (e.g., Hoskins et al. 1985) or is eventually reentrained as a result of an upstream shortwave disturbance. While COL are detached from the waveguide they can provide dynamic and thermodynamic mechanisms to enhance vertical motion and precipitation (e.g., Singleton and Reason 2007a), including both 1) coherent large-scale stratiform precipitation upstream of the parent low as warm, moist air is advected along 
the warm conveyor belt and 2) convective precipitation near the COL center as cold air in the mid- to upper troposphere destabilizes the atmosphere. Unlike most progressive midlatitude disturbances, the quasi-stationary nature of COL can foster prolonged uplift over a region for a multiday period and has been associated with very large precipitation events and precipitation rates in South Africa (Singleton and Reason 2007a,b), Australia (Griffiths et al. 1998), eastern Asia (Hu et al. 2010), and southern Europe (e.g., Porcù et al. 2007) and in a few case studies across the United States (NielsenGammon et al. 2005; Shepherd et al. 2011). In a more recent event, a quasi-stationary COL over northern Florida in early October of 2015 provided favorable upper-tropospheric dynamics conducive to upward motion and facilitated strong southeasterly moisture flux from the outflow of Hurricane Joaquin to produce historic rainfall accumulations across South Carolina, just northeast of the COL center.

The contribution of COL to both seasonal precipitation and precipitation extremes has been examined in a climatological context in certain parts of the globe (e.g., Pook et al. 2006; Favre et al. 2013; Hu et al. 2010), but no known study has examined the influence of COL on seasonal precipitation, precipitation extremes, and interannual precipitation variability over the United States, although some have conducted regional analyses using closed lows (e.g., Nguyen and DeGaetano 2012; Oakley and Redmond 2014). This study aims to address this void by identifying COL and daily precipitation from stations across the conterminous United States (CONUS) from 1979 to 2014. The collective understanding of COL in shaping precipitation climate, including extreme events and interannual variability, is of diagnostic value and may provide insights to seasonal climate prediction and climate-change projections of regional precipitation.

\section{Data and methods}

Several procedures for identifying COL have been documented in the literature (Nieto et al. 2008). The algorithm of Nieto et al. (2005) was adopted here because it employs several diagnostics that adhere to the conceptual model of a COL near the tropopause. This algorithm identifies COL when four criteria are satisfied: 1) local minimum in 200-hPa geopotential height, 2) easterly flow at $200 \mathrm{hPa}$ immediately north of the COL center, 3) increase in 200-300-hPa thickness east of the COL center, and 4) baroclinic zone at $200 \mathrm{hPa}$ east of the COL center. Daily 0000 UTC fields of 200- and 300 -hPa geopotential height as well as 200-hPa air temperature were acquired from the European Centre for Medium-Range Weather Forecasts interim reanalysis
(ERA-Interim) dataset, covering the 1979-2014 time period at a $2.5^{\circ}$ spatial resolution. The identification of a COL was limited to the northwesternmost pixel when contiguous pixels met the criteria of Nieto et al. (2005).

Daily precipitation from 1218 stations in the CONUS that are part of the Global Historical Climate Network (GHCN) were acquired for 1979-2014. Daily precipitation from 796 high-elevation SNOTEL stations in the mountainous western United States was acquired to supplement the paucity of precipitation data in the region and to examine potential differences in precipitation in complex terrain. SNOTEL data were subject to the quality-control analyses of Serreze et al. (1999). Stations missing more than $10 \%$ of daily precipitation records were excluded from subsequent analyses, leaving a total of $851 \mathrm{GHCN}$ and 425 SNOTEL stations. Extremeprecipitation events were defined as 3-day accumulations exceeding the 95th percentile of nonoverlapping nonzero 3-day precipitation totals, following the method in previous analyses (e.g., Ralph and Dettinger 2012; Parker and Abatzoglou 2016).

Precipitation within $660 \mathrm{~km}\left(\sim 6^{\circ}\right)$ of the centroid and within 1 day before or after the COL was attributed to COL. Although COL vary in spatial extent, an $\sim 6^{\circ}$ radial extent is consistent with the radius that Catto et al. (2012) used to assign precipitation to surface fronts and the radius used by Porcù et al. (2007) in assigning precipitation associated with COL in the Mediterranean Sea region. Other radii between $3^{\circ}$ and $8^{\circ}$ from the COL center produced similar results, albeit with slight differences in magnitude. The padding by 1 day addresses potential differences in time of observation by GHCN stations and reanalysis as well as the transit time of COL (e.g., Oakley and Redmond 2014).

The percent of accumulated precipitation and 3-day precipitation extremes attributed to COL was calculated for each station. Likewise, the number of days each station met the aforementioned COL criteria was tabulated. The interannual relationship between accumulated COL precipitation and total precipitation was quantified in two ways: 1) the Pearson's correlation coefficient and 2) the ratio of standard deviation of total precipitation and standard deviation of total precipitation minus COL precipitation. The latter provides a measure of the interannual contribution of COL to precipitation variability. Results were examined for both annual totals and climatological seasons (e.g., December-February).

\section{Results}

The average number of days per season that stations were within $660 \mathrm{~km}$ of a COL center varied from fewer 


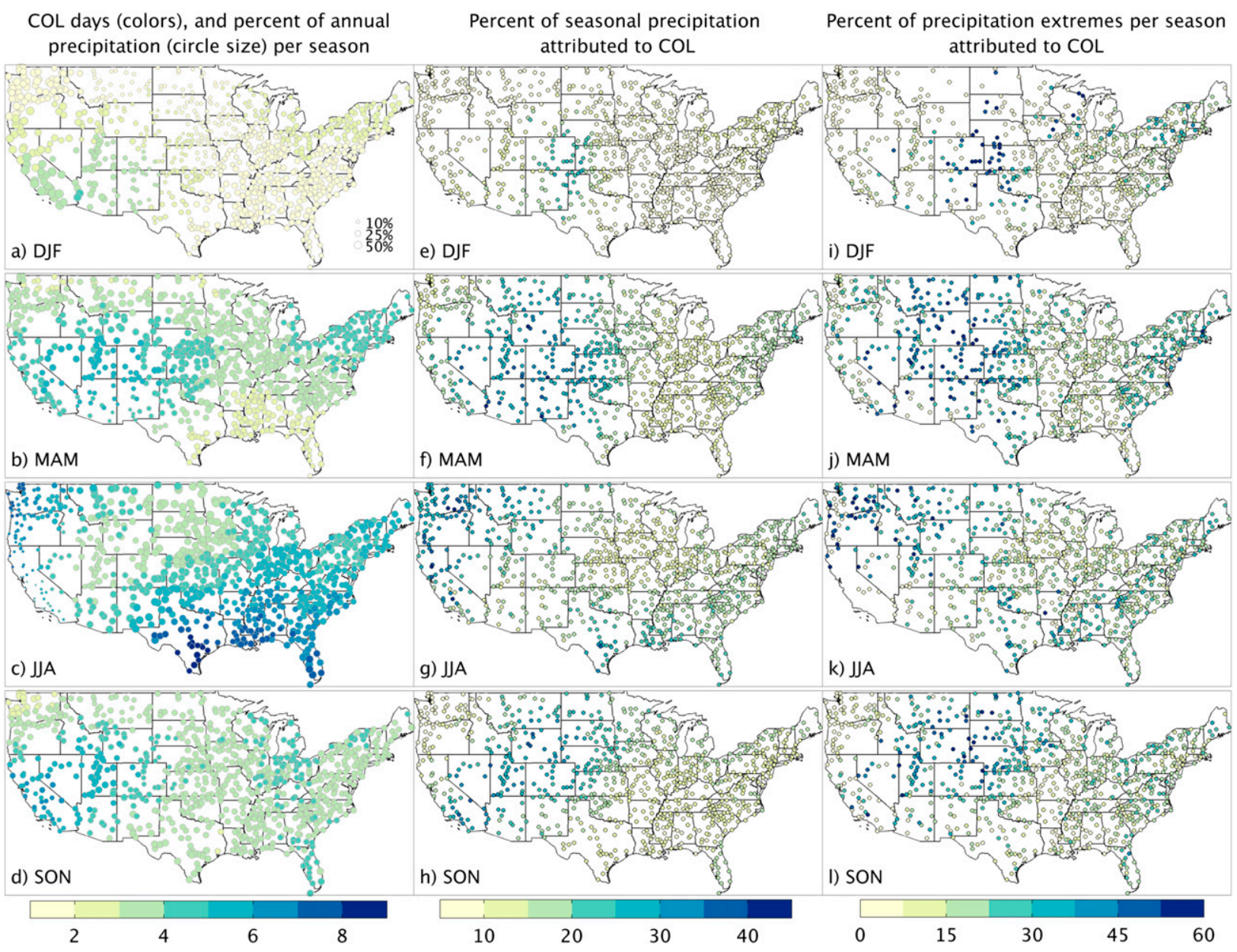

FIG. 1. (a)-(d) Average number of days per season with COL within a 660-km radius, where the area of each circle is proportional to the percent of annual precipitation that occurs in each season, (e)-(h) percent of seasonal precipitation occurring within \pm 1 day and a $660-\mathrm{km}$ radius of identified COL, and (i)-(l) percent of 3-day precipitation extremes concurrent with COL (stations that did not experience extremes during a given season are omitted) for (top) DJF, (top middle) MAM, (bottom middle) JJA, and (bottom) SON.

than 2 days in winter [December-February (DJF)] across much of the United States to more than 10 days in summer [June-August (JJA)] across the southern tier of the United States (Figs. 1a-d). Regional maxima in COL during spring [March-May (MAM)] and autumn [September-November (SON)] were found over the Great Basin and northern California, respectively. On an annual basis, more than 16 days per year met the aforementioned criteria from California eastward to the Colorado Plateau (Fig. S1a in the online supplemental material), similar to the COL climatological description of Nieto et al. (2008). These geographic and seasonal patterns for COL resemble those of Rossby wave breaking located downstream and southward of the jet exit region (e.g., Wernli and Sprenger 2007; Abatzoglou and Magnusdottir 2006).

Over one-third of accumulated precipitation and over one-half of extreme-precipitation events during DJF over the west-central Great Plains to the front range of the southern Rockies were associated with COL (Figs. 1e,i). Note, however, that a relatively small portion of annual precipitation falls in DJF in this area. Elsewhere COL typically accounted for less than $10 \%$ of DJF precipitation and precipitation extremes. Southeasterly lower-tropospheric flow with COL can result in upslope precipitation enhancement along the eastward flanks of mountains (e.g., Reinking and Boatman 1986). By contrast, these locations experience rain shadowing during typical progressive midlatitude frontal systems in which the flow favors orographic precipitation enhancement on western windward slopes at higher elevations (e.g., Mahoney et al. 2015; Roe 2005).

Over one-third of the accumulated precipitation and precipitation extremes during MAM were attributed to COL across much of the interior western United States and Great Plains, with the largest relative contribution over the southwestern United States and in the lee of 
a) Percent of Annual PPT as COL

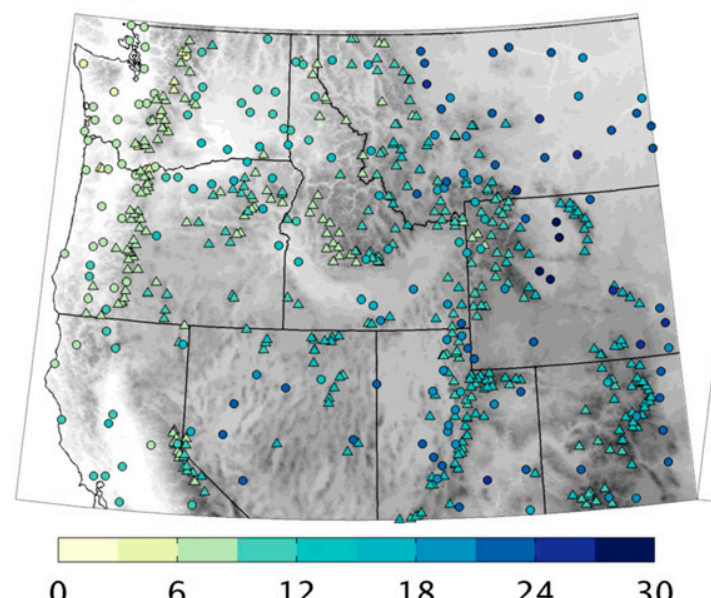

b) Percent of Annual PPT Extremes as COL

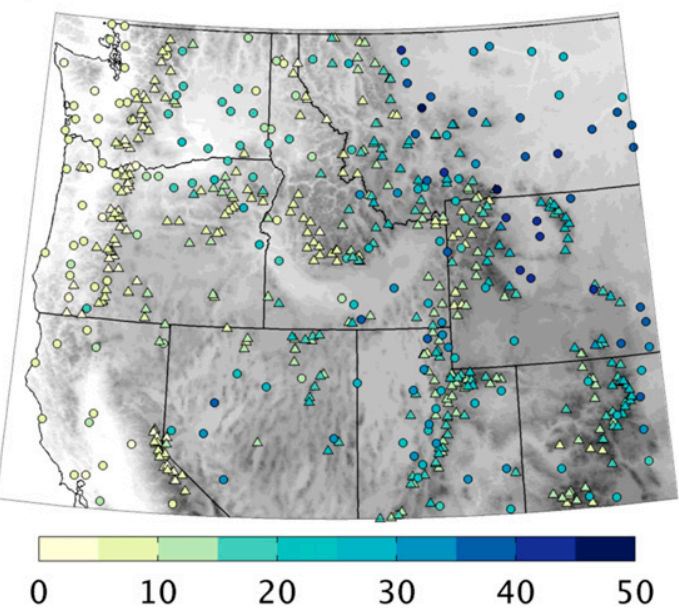

FIG. 2. Percent of annual (a) precipitation and (b) 3-day precipitation extremes attributed to COL. GHCN stations are shown by circles. SNOTEL stations are shown by triangles.

both the Sierra Nevada and the northern and middle Rockies (Figs. 1f,j). Likewise, over one-third of JJA precipitation and precipitation extremes were attributed to COL over the northwestern United States and western Great Basin (Figs. 1g,k). Prior studies have alluded to COL facilitating the northward advection of moisture from the North American monsoon toward these regions (e.g., Carleton 1986; Favors and Abatzoglou 2013). These regions typically lack lower-tropospheric moisture or uplift mechanisms for producing precipitation during JJA and receive a small portion of their annual precipitation during this season (Fig. 1c). Occasional COL that affect these regions in summer can overcome limitations of moisture and dynamics and create atmospheric conditions conducive to precipitation. The areas along a southwest-northeast transect from Southern California to the northern Great Plains receive over $25 \%$ of their SON precipitation with COL (Figs. 1h,l). Previous studies have suggested that COL facilitate the advection of tropical moisture, including remnants from tropical storms, into the western United States during the autumn (Mock 1996).

COL contribute between $2 \%$ and $32 \%$ of mean annual precipitation, with the largest percentages found in the lee of the Rockies and at lower elevations in the Great Basin (Fig. 2; maps for the CONUS in supplemental Fig. S1). Gradients in the contribution of COL to annual precipitation are evident orthogonal to northsouth-oriented mountain barriers in the western United States. For example, COL contribute approximately $10 \%$ of annual precipitation for mountains stations west of the Continental Divide (e.g., near Glacier National Park) as compared with $20 \%-25 \%$ for stations located less than $50 \mathrm{~km}$ east of the mountains in the northern Great Plains. In a similar way, stations in the lee of the Wind River and Absaroka Ranges in northwestern Wyoming receive $\sim 30 \%$ of their annual precipitation with COL as compared with typically less than $15 \%$ of the annual precipitation at higher elevations occurring with COL. In addition, there is a preference for a relatively higher proportion of annual precipitation to occur with COL at lower-elevation sites across the interior western United States than at adjacent mountain sites. The equivalent barotropic flow associated with a COL does not promote orographic precipitation enhancement in areas that typically are favored during westerly-to-southwesterly lower-tropospheric flow associated with progressive frontal systems. Differences in interannual precipitation variability with orography have demonstrated links to the strength of the lowertropospheric zonal winds (e.g., Dettinger et al. 2004; Luce et al. 2013). Likewise, variability in large-scale flow that facilitates COL could contribute to elevational differences in precipitation at interannual time scales.

Nearly one-half of all stations exhibited statistically significant positive correlations (significance level $p<$ 0.05 ) between seasonal COL precipitation and total seasonal precipitation at interannual time scales, ranging from $16 \%$ to $60 \%$ of stations in DJF and JJA, respectively (Fig. 3). Positive correlations between COL precipitation and seasonal precipitation during JJA were seen across nearly all of the United States except the Midwest and the Great Lakes. The strongest JJA correlations were found across the northwestern United States, where COL explained an average of $26 \%$ of the 


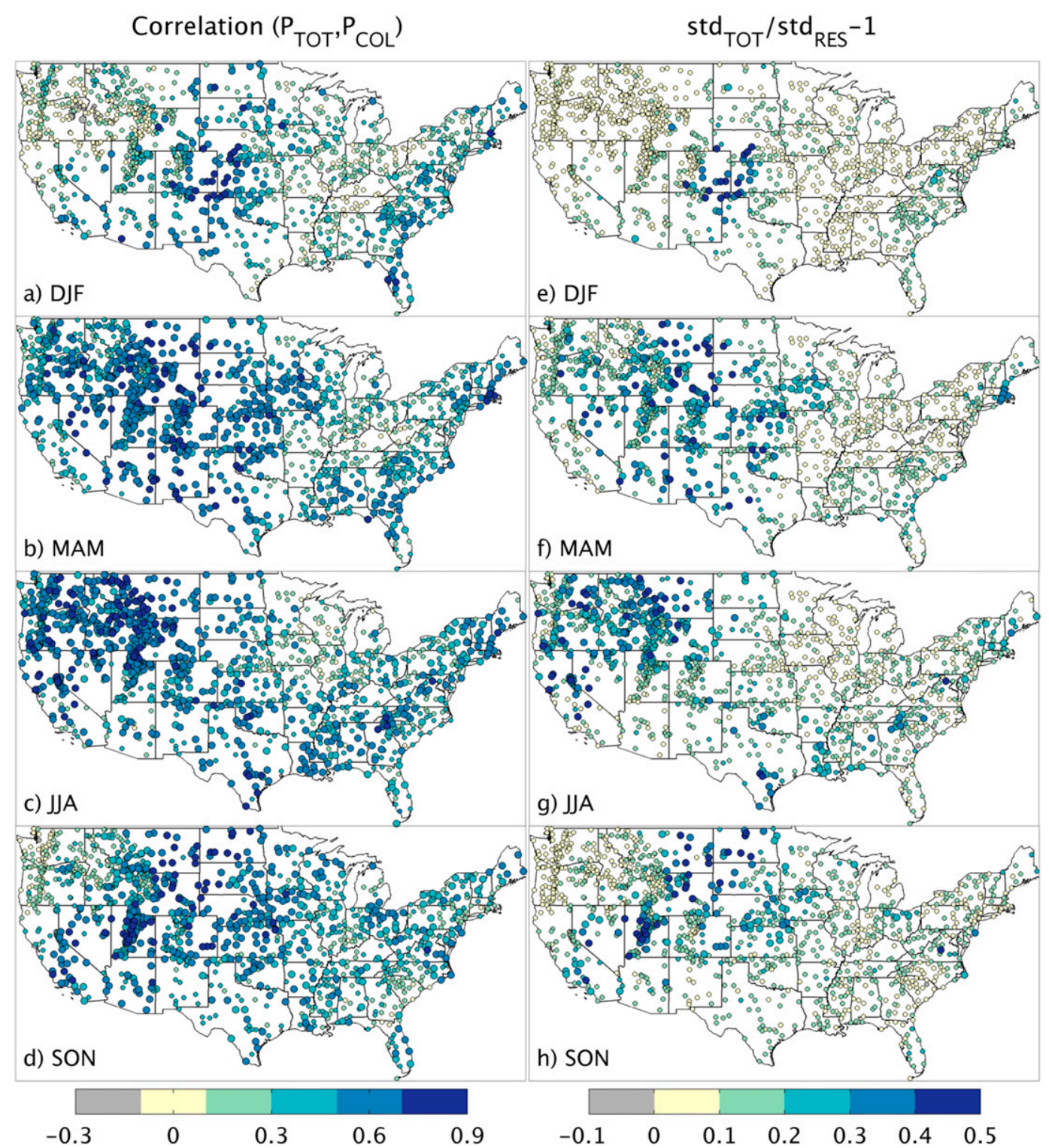

FIG. 3. (a)-(d) Interannual correlation between COL precipitation and total precipitation. (e)-(h) Ratio of total standard deviation of seasonal precipitation to the standard deviation of seasonal precipitation excluding COL minus 1. Positive values indicate that COL precipitation increases interannual precipitation variability. Large symbols represent statistically significant $(p<0.05)$ correlations in (a) $-(\mathrm{d})$ and reductions of $>20 \%$ in (e)-(h) Maps are provided for (top) DJF, (top middle) MAM, (bottom middle) JJA, and (bottom) SON.

variance in JJA precipitation. Strong widespread correlations were also found during MAM and SON across the interior western United States and Great Plains. Conversely, correlations between precipitation attributed to COL and total residual seasonal precipitation (total minus that attributed to COL; not shown) were weak, with approximately $2.5 \%$ of all stations having statistically significant positive correlations for the different seasons. Complementary to the correlation analysis, the magnitude of interannual precipitation variability was reduced substantially upon excluding COL precipitation (Figs. 3e-h). In many regions over the western half of the United States, the magnitude of interannual variability by season was reduced by over $30 \%$.

\section{Conclusions}

COL have distinct geographic and seasonal influences on precipitation over the CONUS, as has been demonstrated in midlatitudes elsewhere on the globe (e.g., 
Pook et al. 2006). COL contribute over $20 \%$ of annual precipitation across much of the interior portions of the western United States and the Great Plains and over one-third of all 3-day precipitation extremes across parts of the semiarid western United States, including the Great Basin and central to northern Great Plains, some of which have been associated with flooding hazards (e.g., Szeto et al. 2011). Stark gradients in the relative importance of COL to annual precipitation across north-south-oriented mountains in the western United States likely arise as a consequence of differences in lower-tropospheric cross-barrier flow associated with COL versus that associated with progressive midlatitude fronts. Although similar macroscale patterns were seen using ERA-Interim precipitation (supplemental Fig. S2), the lack of mesoscale COL precipitation characteristics in regions of complex terrain in coarse-scale reanalyses highlights the importance of the observational network.

Precipitation attributed to COL was disproportionately of higher importance in regions and seasons for which precipitation is sparse. For example, COL contributed over one-third of growing-season (springsummer) precipitation across the semiarid northern Great Plains, supporting the viability of dryland farming and ranching that is dependent on supplemental moisture. Likewise, COL contribute to both the mean climatological behavior and interannual variability of summer precipitation across the northwestern United States. Although these regions receive a relatively small portion of annual precipitation in summer, precipitation that does occur is of importance in dryland agriculture, in reducing irrigation demand for irrigated agriculture, and in quelling wildfire potential (e.g., Abatzoglou and Kolden 2013).

Precipitation attributed to COL explained a significant portion of the overall interannual variability of seasonal precipitation across many portions of the United States, most notably during JJA. Prior analyses have demonstrated interannual relationships between large-scale modes of climate variability and COL in Europe, South Africa, and Australia (e.g., Favre et al. 2013). Correlations of seasonal COL precipitation over the CONUS with concurrent indices of $\mathrm{El} \mathrm{Niño-}$ Southern Oscillation (ENSO, using the multivariate ENSO index), the Pacific-North American (PNA) pattern, and the Arctic Oscillation (AO) reveal a few coherent relationships in regions where COL was important to seasonal precipitation (supplemental Fig. S3). The most notable positive correlations were found between spring COL precipitation and both ENSO and PNA over parts of the Intermountain West and Mid-Atlantic regions, as well as between summer COL precipitation and ENSO over the northwestern United States.
Although widespread correlations were found in other combinations (e.g., winter $\mathrm{AO}$ and precipitation over the Midwest), a very small percentage of seasonal precipitation in these regions was attributed to COL. Additional analyses may further investigate interannual relationships among background upper-tropospheric flow, lower-tropospheric moisture flux, and COL precipitation.

The importance of COL to seasonal precipitation across the CONUS has relevancy for observed precipitation trends as well as regional precipitation projections. No significant linear trends in COL precipitation were found over the short period of analysis, except for positive trends in $\sim 20 \%$ of stations from Indiana-Illinois southwestward into Arkansas and northern Alabama (supplemental Fig. S4), which receive an average of only $\sim 10 \%$ of their annual precipitation from COL (supplemental Fig. S1b). Changes in the frequency and geography of certain atmospheric circulation patterns such as COL may arise as a result of anthropogenic climate change during the twenty-first century (e.g., Grose et al. 2012), however, and have subsequent implications for regional precipitation projections. The evaluation of GCM simulations for their usage in regional climate projections has typically focused on monthly output (e.g., Rupp et al. 2013). Evaluating the credibility of daily synoptic fields simulated by GCMs might be warranted for regions where COL contribute a substantial portion of seasonal precipitation.

Acknowledgments. This research was supported by the National Institute of Food and Agriculture Competitive Grant, Award 2011-68002-30191. I also acknowledge the valuable feedback from three anonymous reviewers who helped to improve the content of this paper.

\section{REFERENCES}

Abatzoglou, J. T., and G. Magnusdottir, 2006: Planetary wave breaking and nonlinear reflection: Seasonal cycle and interannual variability. J. Climate, 19, 6139-6152, doi:10.1175/ JCLI3968.1.

— , and C. A. Kolden, 2013: Relationships between climate and macroscale area burned in the western United States. Int. J. Wildland Fire, 22, 1003-1020, doi:10.1071/WF13019.

Carleton, A. M., 1986: Synoptic-dynamic character of 'bursts' and 'breaks' in the south-West U.S. summer precipitation singularity. J. Climatol., 6, 605-623, doi:10.1002/joc.3370060604.

Catto, J. L., C. Jakob, G. Berry, and N. Nicholls, 2012: Relating global precipitation to atmospheric fronts. Geophys. Res. Lett., 39, L10805, doi:10.1029/2012GL051736.

Dettinger, M. D., 2013: Atmospheric rivers as drought busters on the U.S. West Coast. J. Hydrometeor., 14, 1721-1732, doi:10.1175/JHM-D-13-02.1.

- K. Redmond, and D. Cayan, 2004: Winter orographic precipitation ratios in the Sierra Nevada-Large-scale atmospheric 
circulations and hydrologic consequences. J. Hydrometeor., $\mathbf{5}$, 1102-1116, doi:10.1175/JHM-390.1.

_ , F. M. Ralph, T. Das, P. J. Neiman, and D. R. Cayan, 2011: Atmospheric rivers, floods and the water resources of California. Water, 3, 445-478, doi:10.3390/w3020445.

Favors, J. E., and J. T. Abatzoglou, 2013: Regional surges of monsoonal moisture into the southwestern United States. Mon. Wea. Rev., 141, 182-191, doi:10.1175/MWR-D-12-00037.1.

Favre, A., B. Hewitson, C. Lennard, R. Cerezo-Mota, and M. Tadross, 2013: Cut-off lows in the South Africa region and their contribution to precipitation. Climate Dyn., 41, 23312351, doi:10.1007/s00382-012-1579-6.

Griffiths, M., M. J. Reeder, D. J. Low, and R. A. Vincent, 1998 : Observations of a cut-off low over southern Australia Quart. J. Roy. Meteor. Soc., 124, 1109-1132, doi:10.1002/ qj.49712454805.

Grose, M. R., M. J. Pook, P. C. McIntosh, J. S. Risbey, and N. L. Bindoff, 2012: The simulation of cutoff lows in a regional climate model: Reliability and future trends. Climate Dyn., 39, 445-459, doi:10.1007/s00382-012-1368-2.

Hoskins, B. J., M. E. McIntyre, and A. W. Robertson, 1985: On the use and significance of isentropic potential vorticity maps. Quart. J. Roy. Meteor. Soc., 111, 877-946, doi:10.1002/ qj. 49711147002.

Hu, K., R. Lu, and D. Wang, 2010: Seasonal climatology of cutoff lows and associated precipitation patterns over northeast China. Meteor. Atmos. Phys., 106, 37-48, doi:10.1007/ s00703-009-0049-0.

Luce, C. H., J. T. Abatzoglou, and Z. A. Holden, 2013: The missing mountain water: Slower westerlies decrease orographic enhancement in the Pacific Northwest USA. Science, 342, 13601364, doi:10.1126/science.1242335.

Lute, A. C., and J. T. Abatzoglou, 2014: Role of extreme snowfall events in interannual variability of snowfall accumulation in the western United States. Water Resour. Res., 50, 2874-2888, doi:10.1002/2013WR014465.

Mahoney, K., F. M. Ralph, K. Wolter, N. Doesken, M. Dettinger, D. Gottas, and A. White, 2015: Climatology of extreme daily precipitation in Colorado and its diverse spatial and seasonal variability. J. Hydrometeor., 16, 781-792, doi:10.1175/ JHM-D-14-0112.1.

Mock, C. J., 1996: Climatic controls and spatial variations of precipitation in the western United States. J. Climate, 9, 1111-1125, doi:10.1175/1520-0442(1996)009<1111: CCASVO $>2.0 . \mathrm{CO} ; 2$.

Ndarana, T., and D. W. Waugh, 2010: 2010, The link between cut-off lows and Rossby wave breaking in the Southern Hemisphere. Quart. J. Roy. Meteor. Soc., 136, 869-885, doi:10.1002/qj.627.

Nguyen, L. T., and A. T. DeGaetano, 2012: A climatology of $500-\mathrm{hPa}$ closed lows and associated precipitation in the northeastern United States. J. Appl. Meteor. Climatol., 51, 3-15, doi:10.1175/JAMC-D-10-05028.1.

Nielsen-Gammon, J. W., F. Zhang, A. M. Odins, and B. Myoung, 2005: Extreme rainfall in Texas: Patterns and predictability. Phys. Geogr., 26, 340-364, doi:10.2747/0272-3646.26.5.340.

Nieto, R., and Coauthors, 2005: Climatological features of cutoff low systems in the Northern Hemisphere. J. Climate, 18, 30853103, doi:10.1175/JCLI3386.1.

, L. Gimeno, L. De la Torre, P. Ribera, D. Barriopedro, R. García-Herrera, and J. Lorente, 2007: Interannual variability of cut-off low systems over the European sector: The role of blocking and the Northern Hemisphere circulation modes. $\mathrm{Me}$ teor. Atmos. Phys., 96, 85-101, doi:10.1007/s00703-006-0222-7.
—- M. Sprenger, H. Wernli, R. M. Trigo, and L. Gimeno, 2008: Identification and climatology of cut-off lows near the tropopause. Ann. N. Y. Acad. Sci., 1146, 256-290, doi:10.1196/ annals.1446.016.

Oakley, N. S., and K. T. Redmond, 2014: A climatology of 500-hPa closed lows in the northeastern Pacific Ocean, 1948-2011. J. Appl. Meteor. Climatol., 53, 1578-1592, doi:10.1175/ JAMC-D-13-0223.1.

Parker, L. E., and J. T. Abatzoglou, 2016: Spatial coherence of extreme precipitation events in the northwestern United States. Int. J. Climatol., doi:10.1002/joc.4504, in press.

Pook, M. J., P. C. McIntosh, and G. A. Meyers, 2006: The synoptic decomposition of cool-season rainfall in the southeastern Australian cropping region. J. Appl. Meteor. Climatol, 45, 1156-1170, doi:10.1175/JAM2394.1.

Porcù, F., A. Carrassi, C. M. Medaglia, F. Prodi, and A. Mugnai, 2007: A study on cut-off low vertical structure and precipitation in the Mediterranean region. Meteor. Atmos. Phys., 96, 121-140, doi:10.1007/s00703-006-0224-5.

Ralph, F. M., and M. D. Dettinger, 2012: Historical and national perspectives on extreme West Coast precipitation associated with atmospheric rivers during December 2010. Bull. Amer. Meteor. Soc., 93, 783-790, doi:10.1175/BAMS-D-11-00188.1. , P. J. Neiman, G. A. Wick, S. I. Gutman, M. D. Dettinger, D. R. Cayan, and A. B. White, 2006: Flooding on California's Russian River: Role of atmospheric rivers. Geophys. Res. Lett., 33, L13801, doi:10.1029/2006GL026689.

Reinking, R. F., and J. F. Boatman, 1986: Upslope precipitation events. Mesoscale Meteorology and Forecasting, P. S. Ray, Ed., Amer. Meteor. Soc., 437-471.

Roe, G. H., 2005: Orographic precipitation. Annu. Rev. Earth Planet. Sci., 33, 645-671, doi:10.1146/annurev.earth.33.092203.122541.

Rupp, D. E., J. T. Abatzoglou, K. C. Hegewisch, and P. W. Mote, 2013: Evaluation of CMIP5 20th century climate simulations for the Pacific Northwest USA. J. Geophys. Res. Atmos., 118, 10 884-10 906, doi:10.1002/jgrd.50843.

Rutz, J. J., W. J. Steenburgh, and F. M. Ralph, 2014: Climatological characteristics of atmospheric rivers and their inland penetration over the western United States. Mon. Wea. Rev., 142, 905-921, doi:10.1175/MWR-D-13-00168.1.

Serreze, M. C., M. P. Clark, R. L. Armstrong, D. A. McGinnis, and R. S. Pulwarty, 1999: Characteristics of the western United States snowpack from snowpack telemetry (SNOTEL) data. Water Resour. Res., 35, 2145-2160, doi:10.1029/ 1999WR900090.

Shepherd, M., T. Mote, J. Dowd, M. Roden, P. Knox, S. C. McCutcheon, and S. E. Nelson, 2011: An overview of synoptic and mesoscale factors contributing to the disastrous Atlanta flood of 2009. Bull. Amer. Meteor. Soc., 92, 861-870, doi:10.1175/2010BAMS3003.1.

Singleton, A. T., and C. J. C. Reason, 2007a: A numerical model study of an intense cutoff low pressure system over South Africa. Mon. Wea. Rev., 135, 1128-1150, doi:10.1175/MWR3311.1.

- and $-2007 \mathrm{~b}$ : Variability in the characteristics of cut-off low pressure systems over subtropical southern Africa. Int. J. Climatol., 27, 295-310, doi:10.1002/joc.1399.

Szeto, K., W. Henson, R. Stewart, and G. Gascon, 2011: The catastrophic June 2002 prairie rainstorm. Atmos.-Ocean, 49, 380395, doi:10.1080/07055900.2011.623079.

Wernli, H., and M. Sprenger, 2007: Identification and ERA-15 climatology of potential vorticity streamers and cutoffs near the extratropical tropopause. J. Atmos. Sci., 64, 1569-1586, doi:10.1175/JAS3912.1. 